\title{
Selection of Biomarkers from Differentially Expressed Genes in Leukocytes of Buffalos Treated with Recombinant Bovine Somatotropin: The Importance of Sample Size for Reliable Discriminating Systems
}

\author{
Lorenzo Castigliego ${ }^{1, *}$, Filippo Jodi Carrieri ${ }^{1}$, Andrea Armani ${ }^{1}$, Marco Mazzi ${ }^{2}$, Carlo Boselli ${ }^{3}$, \\ Goffredo Grifoni ${ }^{3}$, Daniela Gianfaldoni ${ }^{1}$ and Alessandra Guidi ${ }^{1}$ \\ ${ }^{1}$ Department of Veterinary Sciences, University of Pisa, Via delle Piagge 2, 56124 Pisa, Italy \\ ${ }^{2}$ Animal Production Research Centre (PCM), Agriculture Research Council (CRA), Via Salaria, 31, I-00015 \\ Monterotondo, Rome, Italy \\ ${ }^{3}$ Experimental Zooprophylactic Institute of Lazio and Tuscany, Via Appia Nuova 1411, I-00178 Rome, Italy
}

\begin{abstract}
The research on biomarkers to detect livestock treated with recombinant bovine somatotropin (rbST) is still an open issue. In fact, beyond undertaking confirmation methods, there is the need to develop simple and inexpensive screening tests. In this direction, some proposals have been forwarded, mostly involving the measurement of circulating molecules, whereas the possibility of using biomarkers related to gene expression is a field under investigation. The present study was carried out on sixteen buffalos, eight of which treated with rbST. Blood samples were collected six times during the treatment to investigate on the presence of differentially expressed genes in leukocytes. Analysis with the microarray technique was performed on two sampling moments, in order to obtain a first selection of genes. Further analysis was carried out by real time RT-PCR, in order to create a discriminating linear system. A study on the variation of the error related to the number of samples included in statistics was also performed. Results showed that, including an increasing number of samples to build the discriminating algorithm, the $\beta$-error grows and tends to stabilize on $6.5 \%$. This study clearly shows the paramount importance of including a proper number of samples to obtain reliable algorithms.
\end{abstract}

Keywords: Recombinant bovine somatotropin, Buffalos, Biomarkers, Screening tests, Sample size.

\section{INTRODUCTION}

The use of biomarkers is becoming more and more popular, both in medicine, for indication or diagnosis on possible diseases, and in legal analysis addressed to reveal doping abuse in sports and illegal or undeclared pharmacological treatment in livestock [1-5]. This is due to the fact that biomarkers may be often easily quantified or create characteristic patterns that may be profiled in a more simple and cheaper way than other direct methods, such as the research and quantification of residues in biological materials. For this reason, the research of biomarkers is one of the possible approaches used in screening tests, which requires less effort and usually provides a higher throughput than confirmation methods. Performance of screening tests is regulated by law. In the European Union, Decision 2002/657/EC clearly delivers some validation requirements that screening methods must fulfill in order to be considered applicable in field [6].

One particular case that involves studies on the possibility to set up reliable screening tests based on

${ }^{*}$ Address correspondence to this author at the Department of Veterinary Sciences, University of Pisa, Via delle Piagge 2, 56124, Pisa, Italy; Tel: +39 050 2210211; Fax: +39 050 2210213; E-mail: lorenzo.castigliego@unipi.it

ISSN: 1927-5196 / E-ISSN: 1927-520X/16 biomarkers is the abuse of rbST-based drugs for increasing yield in lactating cows and buffalos. In fact, rbST is a synthetic peptide hormone available on the market, which is legal in some countries, such as the USA, and prohibited in other, such as the member states of the European Union (Dec 1999/879/EC) [7]. The use and misuse of rbST has always been the core of many controversies and controls on possible hormonal treatments have always been difficult due to the high identity between the recombinant molecules and the natural ones. Beyond some confirmation methods based on mass spectrometry [8-10], which require specialized personnel and expensive instrumentations, efforts have been made to develop cheaper and more widely applicable tests. In this direction, different approaches have been proposed, from the research and quantification of molecules recognizing the somatotropin in serum [11-13], through the combined research of a number of different molecules, the concentration of which may vary in serum responding to the rbST treatment cows [14-18], unto the quantification of the alteration of gene expression in different tissues $[19,20]$.

In this work, with the purpose of finding a typical pattern of gene expression in white blood cells, we 
analyzed a number of sera collected from treated buffalos, comparing them to sera from untreated animals, by the technique of the microarray, in order to find a plethora of genes differentially expressed in the two groups to be used as biomarkers for the treatment. Once identified, these genes were analyzed by real time RT-PCR in a greater number of samples, in order to more precisely quantify their expression level and evaluate the possibility to include them in a model that is able to discriminate between treated and non-treated animals. Furthermore, in this work, we show how the number of samples analyzed is important in producing reliable responses and how several statistical parameters, which are associated to the test response, may change with the step-by-step addition of new samples, until the stabilization of the outcome.

\section{MATERIALS AND METHODS}

\section{Experimental Design and Sample Collection}

Sixteen Mediterranean Italian buffalos were selected from the Animal Production Research Centre of Tormancina (Italy) and were managed in standard conditions with ad libitum feeding and fresh water always available. In both studies, the animals were randomly allotted to two groups. One group was assigned to the rbST treatment $(n=8)$ and the other served as the controls $(n=8)$. Overall, sera were available from sixteen treated and sixteen control buffalos.

Treatment was performed by administering a sustained release formulation $(500 \mathrm{mg}$ in $2 \mathrm{ml}$ of vehicle) of rbST (Boostin $®$, from LG Life Sciences, Seoul, Korea) by subcutaneous injections in the tail head area, as suggested for cows by the drug manufacturer. Controls were injected with a saline physiological solution.

The animals were under veterinary surveillance during the whole experimental period and underwent a weekly clinical examination in order to monitor their state of health.

The treatment lasted twelve weeks, starting from the tenth week post partum, for a total of six (named $A$, $B, C, D, E, F$ ) biweekly cycles of administration.

Blood was collected via venipuncture of the jugular vein into Tempus TM Blood RNA Tube (Life Technologies Corporation, Carlsbad, CA, USA) tubes containing $6 \mathrm{ml}$ of a special reagent stabilizer, to inactivate the RNase phones and selectively precipitate
RNA. The samples were immediately submitted to the extraction of RNA. Sampling was carried out within cycles $B, C$, and $D$, before the first meal of the day, on days 2 , and 5 after each rbST administration. Sampling moment is the name that will be given to a precise moment of sampling and it will be indicated with the letter of the cycle of rbST administration followed by the number of the day after rbST injection (i.e. B2; C5; etc.). A total number of 96 samples were processed.

\section{RNA Extraction}

Total RNA was extracted from leukocytes using the extraction kit Tempus ${ }^{T M}$ Spin RNA Isolation Reagent Kit (Applied Biosystems, Foster City, CA, USA), according to the procedure suggested by the manufacturer. The amount of extracted RNA was evaluated with a spectrophotometer NanoDrop ND-1000 (NanoDrop Technologies, Wilmington, DE, US), by measuring the absorbance at $260 \mathrm{~nm}$. The purity of the nucleic acids was evaluated, based on the ratio of absorbance at $260 / 280 \mathrm{~nm}$ and $260 / 230 \mathrm{~nm}$. The level of fragmentation of the RNA was then evaluated by electrophoresis on agarose gel $1 \%$ (GellyPhorLE®Euroclone, Life Sciences Division PV, Italy), in the presence of formaldehyde for visualization of the two bands corresponding, respectively, to the subunits $18 \mathrm{~s}$ and $28 \mathrm{~s}$ of the rRNA and observed by UV transillumination. Samples from the sampling moments B5 and D5 were analyzed by capillary electrophoresis by the service laboratory that performed the microarray analysis (see paragraph 2.3).

Subsequently, $0.5 \mu \mathrm{g}$ of RNA extracted was treated with the enzyme DNase, necessary to remove any residual DNA, and reverse transcribed into cDNA using QuantiTect Reverse Transcription Kit (Qiagen, Hilden, Germany), following the procedure described by the manufacturer, in a final volume of $30 \mu \mathrm{l}$. The obtained cDNA was then stored at a temperature of $-80{ }^{\circ} \mathrm{C}$ before real-time PCR.

\section{Choice of the Reference Genes}

The screening analysis to identify genes differentially expressed in animals treated with rbST and in the controls was carried out using the microarray technique, commissioned to The Finnish and Microarray sequencing Centre, Turku Centre for Biotechnology (Tykistökatu, Turku, Finland). In brief, the type of chip used in this study was the Agilent's Bovine Gene Expression V2 array (Agilent, Santa Clara, CA, USA), a platform of about 43,000 genes. In 
Table 1: Characteristics of the Primers Designed for Amplification of the Candidate Genes

\begin{tabular}{|c|c|c|c|}
\hline Gene & Primers' sequence & $\begin{array}{l}\text { Theoretic Melting } \\
\text { Temperature }\left({ }^{\circ} \mathrm{C}\right)\end{array}$ & Ampliconlength (bp) \\
\hline$A Q P 3$ & CCTCAATGGGCTTCAACTCTGG & 58,3 & 165 \\
\hline \multirow[t]{2}{*}{ BIRC5 } & TGGCAGCTCTACCTCAAGGAC & 58,3 & \multirow[t]{2}{*}{125} \\
\hline & TCGTTCTCAGTGGGACAGTGG & 58,5 & \\
\hline$B \cup B 1$ & GGGTGTGCTGGTTTGCTACC & 58,1 & 189 \\
\hline \multirow[t]{2}{*}{$B \cup B 1 B$} & TTTAGCCCAACGAAGACCTCTTG & 58,1 & \multirow[t]{2}{*}{139} \\
\hline & CCTGAAACCTGTGATAATAGCATCC & 57,2 & \\
\hline$C D C 20$ & CAGACCTTCACCCAGCATCAAG & 58,3 & 149 \\
\hline \multirow[t]{2}{*}{ CDKN3 } & TGAGAGGATCTGGAGCGATACAG & 58,3 & \multirow[t]{2}{*}{96} \\
\hline & GTGAATTTCTTGATGAAAGGTGTGC & 57,3 & \\
\hline \multirow[t]{2}{*}{ CENPF } & CCTGGAGGCTGCGTTGC & 56,9 & \multirow[t]{2}{*}{192} \\
\hline & CTTGAGTTCAGTTGACCTTCTTGG & 57,2 & \\
\hline \multirow[t]{2}{*}{ DLGAP5 } & CAGCAATCTGACCAAACTTGAGG & 57,4 & \multirow[t]{2}{*}{131} \\
\hline & CAGCAATTCTTCCACCATCATCC & 57,2 & \\
\hline \multirow[t]{2}{*}{ EMP3 } & GACGGAGGGAGGGAGAAAGG & 57,9 & \multirow[t]{2}{*}{170} \\
\hline & TCAAGAGGTTGTTGGCACAGG & 57,6 & \\
\hline KIF2C & GTCGGAGCATTGTGGTAGAGTAG & 57,8 & 130 \\
\hline \multirow[t]{2}{*}{ KIF4A } & GATAAGCGGAAAGAGTCTCAGAGTC & 58,4 & 125 \\
\hline & AGGTCATTCAGATGGCGTTTGG & 58,3 & \\
\hline LMAN1 & GATCAATAACGGCTTCACACCAG & 57,3 & 177 \\
\hline & GGCTCCTTCCCAGGCTCAG & 58,3 & \\
\hline LMTK2 & CGGCAGCAGCACGTCAAG & 58,2 & 73 \\
\hline & GCAGGATGTCATACCAGTAGTCC & 57,5 & \\
\hline $10 c 539953$ & CTGAAGTGGTAGGCAAAGAGAATAG & 56,9 & 180 \\
\hline & GCATGGAGCTGGGAGTAATGG & 57,7 & \\
\hline$L Z B 1$ & CGCAGCCGAGCATCATGG & 57,8 & 77 \\
\hline & CAGGTAGTGAAAGCAGGTCTTGG & 58,4 & \\
\hline MCM2 & AGTGTGCCTAATTGACGAATTTGAC & 58 & 101 \\
\hline & TGCCCGCCTTGGAGATGG & 58 & \\
\hline$N C A P G$ & GTTCTTGCTCTTTCACGCCTTC & 57,5 & 188 \\
\hline & CTGACAGTTTCTTTCACATCCTTGG & 58 & \\
\hline
\end{tabular}


(Table 1). Continued.

\begin{tabular}{|c|c|c|c|}
\hline Gene & Primers' sequence & $\begin{array}{l}\text { Theoretic Melting } \\
\text { Temperature }\left({ }^{\circ} \mathrm{C}\right)\end{array}$ & Ampliconlength (bp) \\
\hline \multirow[t]{2}{*}{ NDC80 } & AGCAGCAGTTGTGGAATGAGG & 57,7 & \multirow[t]{2}{*}{173} \\
\hline & GTTGGCACCAGCGTCAGG & 57,4 & \\
\hline \multirow[t]{2}{*}{ NUSAP1 } & GGAAGACTCTCTGTGGCTTGTAC & 57,9 & \multirow[t]{2}{*}{183} \\
\hline & CTTGGTCAGTGAACGCTTATGC & 57,3 & \\
\hline \multirow[t]{2}{*}{ ORC1 } & AGTGGTGCCTTCTGTGATTCTG & 57,6 & \multirow[t]{2}{*}{111} \\
\hline & GAACTCTTCCTGCGGATACGG & 57,4 & \\
\hline \multirow[t]{2}{*}{$R A C G A P 1$} & CATCTGGCAGCATTCAACTAAGTG & 58 & \multirow[t]{2}{*}{161} \\
\hline & GGATTCATCGGTCTTGTCAAAGC & 57,5 & \\
\hline \multirow[t]{2}{*}{$R A D 54 L$} & GACCTGCTATATCTATCGCCTACTG & 57,7 & \multirow[t]{2}{*}{117} \\
\hline & TCCACATCCTGCTCCTCATCC & 58,1 & \\
\hline \multirow[t]{2}{*}{ RRM2 } & GCCGCTTTGTCATCTTTCCTATC & 57,3 & \multirow[t]{2}{*}{117} \\
\hline & CCCAGTGCTGAATGTCCTTGG & 58,1 & \\
\hline \multirow[t]{2}{*}{ TNFRSF17 } & GTGTCAGGAGCAAACCGAAGG & 58,4 & \multirow[t]{2}{*}{126} \\
\hline & TGGAGGCAGCGAGCAGAC & 58,1 & \\
\hline \multirow[t]{2}{*}{ TXNDC5 } & ATCCTACGCTCCTCTGGTTCC & 57,8 & \multirow[t]{2}{*}{136} \\
\hline & GGCTGGGTGGGCTCTGG & 57,8 & \\
\hline \multirow[t]{2}{*}{$G A D P H$} & GGCACAGTCAAGGCAGAGAAC & 58,4 & \multirow[t]{2}{*}{112} \\
\hline & CATACTCAGCACCAGCATCACC & 58,4 & \\
\hline \multirow[t]{2}{*}{$S D H A$} & CATAGAAGAACGGGTCCATCCAC & 58,1 & \multirow[t]{2}{*}{172} \\
\hline & GAACTGCACGAACTCCAGGTC & 58,1 & \\
\hline \multirow[t]{2}{*}{ SF3A1 } & AGCACAGCCTCTTCAACTACTTC & 57,9 & \multirow[t]{2}{*}{191} \\
\hline & СТТСТССТССТССТССТТСТТСС & 58,5 & \\
\hline
\end{tabular}

particular, aliquots of RNA extracted from samples collected on the sampling moments B5 and D5 were analyzed. The microarray outcome was processed through the modified t-test $p$-values or FDR (false discovery rate) $p$-values, both proposed by Smyth (2005) [21].

\section{Primer Design}

After obtaining the data from the microarray analysis, primers were designed for amplification of the selected genes using the software Beacon Designer 1.5 (Premier Biosoft International, Palo Alto, CA, USA). Sequences deposited in GenBank corresponding to the candidate genes were aligned and only regions without polymorphisms and spanning at least one intron were chosen. Information concerning the selected primers are shown in Table 1. These primers were tested on genetic material extracted from white blood cells of untreated buffaloes. The amplified cDNA was evaluated by gel electrophoresis and subsequently sequenced by BMR Genomics (Padua, Italy) to verify the actual matching with the corresponding genes.

\section{Real-Time PCR}

The cDNA obtained by reverse transcription was amplified by Real-time PCR, using the Rotor Gene 6000 thermocycler (Corbett Research, Sydney, Australia). Each reaction was carried out in $100 \mu \mathrm{l}$ tubes. The PCR mix was composed of $5 \mu$ l of a SYBR Green mastermix (QuantiTect SYBR Green PCR Kit, Qiagen), $1.5 \mu$ l of a solution containing the forward and reverse primers (final concentration $200 \mathrm{nM}$ ), $1 \mu \mathrm{l}$ of cDNA and $2.5 \mu \mathrm{l}$ of deionized water. For each sample, a negative control was included, in which no template was added. All amplifications were carried out in accordance with the following protocol: $15 \mathrm{~min}$ at $95^{\circ}$ C; 40 cycles of 15 seconds at $95^{\circ} \mathrm{C} ; 30 \mathrm{sec}$ at $55^{\circ} \mathrm{C}$; $12 \mathrm{sec}$ at $72^{\circ} \mathrm{C}$; final extension of $5 \mathrm{~min}$ at $72^{\circ} \mathrm{C}$. At the end of each run, a melting temperature analysis was performed $\left(60^{\circ} \mathrm{C}\right.$ for one minute, with increase of $0.5^{\circ} \mathrm{C}$ every $5 \mathrm{sec}$ up to $95^{\circ} \mathrm{C}$ ) to verify the specificity of amplification. The housekeeping genes used for data normalization (GADPH, SDHA, SF3A1) were selected from eight identified in a previous work [19], through a pilot study on a limited number of samples (5 animals 
for 5 treatment cycles). The data were processed using dedicated software (Genorm and Normfinder) and analyzed. The following formula was used to derive the levels of relative gene expression $(R)$, for each of the target genes:

$$
R=\left(\mathrm{CP}_{\text {ref1 }}{ }^{*} \mathrm{CP}_{\text {ref2 }} \text { * } \mathrm{CP}_{\text {ref3 } 3}\right)^{(1 / 3)}-\mathrm{CP}_{\text {target }}
$$

where $\left(\mathrm{CP}_{\text {ref1 }}{ }^{*} \mathrm{CP}_{\text {ref2 }}{ }^{*} \mathrm{CP}_{\text {ref3 }}\right)^{(1 / 3)}$ is the geometric mean of the CP (Crossing Point) values related to the three reference genes and $\mathrm{CP}_{\text {target }}$ is the value of the target gene CP. Each CP is the product of the geometric mean of duplicates. In this case, the values were not corrected for the efficiency of amplification, as the aim is to measure a relative difference in expression level of a determined gene between the treated group and the group of controls.

\section{Statistics}

The normality of the distributions of values for each variable (level of relative expression of each gene) was tested using the Shapiro-Wilk test; equality of variance between the two groups (treated and controls) was tested by the test $\mathrm{F}$.

The presence of outliers was assessed using the box test.

Statistics were performed on $n=92$ samples out of the 96 processed, because the parameters associated to the genetic material from two samples were unsuitable and $n=2$ samples were removed, because associated to outlier results after box plotting. The degree of significance for differences in the levels of gene expression was calculated on the entire pool of the samples belonging to the two groups by two-tailed Student's test.

\section{Linear Discriminant Analysis (LDA) and Creation of a Classifying Linear System}

Before producing an algorithm able to classify a sample as belonging to treated or untreated animals (linear system), the data obtained after PCR of all samples were processed using a linear discriminant analysis (LDA), able to identify the variables with greater discriminating power.

In particular, discriminant analysis has the aim to divide the subjects of the study population into two groups known a priori (treated and untreated), according to the variables associated to the relative levels of expression of the 28 genes analyzed. These variables were later included in a linear system, elaborated in order to obtain a prediction function that allows to classify subjects belonging to different populations with the same characteristics of the population studied. This linear system was of the type:

$$
Y=a+b_{1} X_{1}+\ldots \ldots \ldots \ldots+b_{n} X_{n}
$$

Where $a=$ intercept of the linear function; $b n=$ coefficient of each value associated with the variable $n ; X n=$ value associated with the variable $n$; $Y=$ response value (ideally $1=$ treated, $0=$ untreated). The classification was made by assigning a threshold value that represents the mean of the values 1 and 0 . As a result, the samples with a value $Y \geq 0.5$ were classified as treated, while samples with $Y$ value $<0.5$ as untreated. This classification system does not provide a range of values between $O$ and 1 , such that the sample would be classified as uncertain.

In order to build a system with classification performance of unknown samples associated to an acceptable level of error (based on the percentage of false negatives $<5 \%$, as per Decision 2002/657/EC) [6], we calculated the number of samples required to obtain a stabilization of variance. Due to the fact that the test $F$ revealed equality of variance between the treated and the untreated groups, the strategy adopted was to calculate the variance for each variable (intended as the expression level of one particular gene) within the two treatment groups, starting from sub-groups represented by samples from each sampling moments (B2; B5; C2; C5; D2; D5; $\mathrm{n}=16$ each group), subsequently adding samples coming from another sampling moment and so on until completion, according to the following scheme:

$$
\begin{gathered}
\operatorname{Var}(\mathrm{B} 2) ; \operatorname{Var}(\mathrm{B} 2+\mathrm{B} 5) ; \operatorname{Var}(\mathrm{B} 2+\mathrm{B} 5+\mathrm{C} 2) ; \operatorname{Var} \\
(\mathrm{B} 2+\mathrm{B} 5+\mathrm{C} 2+\mathrm{C} 5) ; \operatorname{Var}(\mathrm{B} 2+\mathrm{B} 5+\mathrm{C} 2+\mathrm{C} 5+\mathrm{D} 2) ; \operatorname{Var} \\
\text { (B2+B5+C2+C5+D2+D5). }
\end{gathered}
$$

The absolute value of the difference between the mean of the variance calculated on each variable (expression level of each gene) at a certain sampling moment and the mean of the variance calculated by adding the samples of the next sampling moment was used to draw a graph to show the trend of the decrease in this difference $(\mathrm{Y})$ plotted against the progressive steps of samples addition $(X)$. The variance was considered stabilized when the confidence interval at $95 \%$ of this difference was included in a range between the value 0 and the value corresponding to $10 \%$ of the 
mean of the variance calculated including two successive subgroups (Figure 2).

Another approach to evaluate the number of samples to be included in the statistics to produce an efficient and reliable classifying algorithm was to evaluate the stabilization of the error, calculated considering the percentage of samples incorrectly classified (false positive + false negative), the following two ways:

1) Algorithm application "between combinations": a classifying linear system was developed for every possible combination of sampling moments (from 1 to 6 moments, with permutations). Afterwards, it was applied to the total pool of samples (all the sampling moments together). The mean of the absolute error obtained for each was used to build a graph to show the relationship between such error $(Y)$ and the number of combinations (X) (Figure 3 ).

2) Algorithm application "within combinations": a classifying linear system was developed for every possible combination of sampling moments (from 1 to 6moments, with permutations). Afterwards, it was applied within the combination from which it was produced. The mean of the absolute error obtained for each combination was used to build a graph to show the relationship between such error $(Y)$ and the number of combinations (X) (Figure 4).

For statistics the software SPSS 13.0 version 13.0 (IBM, Armonk, NY, USA) and JMP version 5.01 (SAS Institute Inc., Cary, NC, USA) were used.

\section{RESULTS AND DISCUSSION}

\section{Choice of the Biological Target}

The white blood cells are a substrate easy to collect and manipulate and do not requires too invasive operations, such as biopsies. For this reason, the white cells represent one of the best choice for this kind of analysis, in the perspective of its "in field" application for controls. Human studies have shown that ST plays an important role as immune system modulator [22, 23]. In fact, the phagocytic capacity of neutrophils and monocytes are reduced in subjects with deficiency of physiological ST, as well as the activity of natural killer lymphocytes, while they tend to increase following treatment with the hormone [24]. ST seems to also protect cells from the lymphocyte apoptosis induced by glucocorticoids [22]. Even in the bovine species, ST was shown to have some effects on leukocytes, stimulating the proliferation of lymphocytes in vitro [25] and influencing the number of some blood cell types in cows [26] and buffalos [27]. These studies support the hypothesis that the treatment with exogenous bST can affect the expression level of a number of genes in the white cells, making them a good candidate for studies on biomarkers.

\section{Quality of the Extracted Genetic Material}

The spectrophotometer readings performed on RNA extracted showed a good quality of the genetic material. In particular, there were no peaks with absorbance at 280 and $230 \mathrm{~nm}$, attributable, respectively, to the presence of proteins or polypeptide or organic compounds and free nucleic acids and their ratio (260/280 and 260/230) were always between 1.8 and 2.1. Electrophoretic analysis on denaturing gels showed the suitability of all samples for the presence of two net bands corresponding to the rRNA 18S and $28 S$, with the exception of two samples, in which the bands appeared smeared, indicating a possible degradation and fragmentation of the genetic material. These samples were not included in the study. Analyses carried out by capillary electrophoresis showed a perfect condition of the extracted RNA.

\section{Microarrays}

Most of the growth promoters and molecules with anabolic effects mainly act through mechanisms of transcriptional type, which determine an increase/decrease of the synthesis of specific proteins. Investigations of proteomics are therefore a valuable tool to delineate the expression profile characteristic of each species and category of animals and possibly to associate it to a particular pharmacological treatment.

Among the mechanisms that determines a differential expression of proteins, there is the modulation of gene expression, which can be determined using techniques able to quantify the amount of mRNA produced. Recently, microarrays (high-density matrices) have become an important research tool for the scientific world. In particular, the cDNA microarray are able to trace the profile of the pattern of gene expression (transcriptomics analysis) of tens of thousands of genes in a single experiment [28]. Such a huge throughput capacity allows to give precious information that could be lost if other kind of 
analysis were applied, capable to screen a considerably lower number of genes. However, costs of a single analysis are very high. For this reason, monitoring the level of expression of tens thousands gens may be used as a preliminary investigation to select a restricted number of genes to be further analyzed by real-time PCR. This is a more accurate technique capable to quantify the expression changes of the identified genes, to be used to construct mathematical models able to discriminate treated animals.

Recently, this analytical technique has also been applied to the field of inspection of food of animal origin, especially meat, in order to identify any illegal administration of growth promoters (corticosteroids, sex hormones) in animals after slaughtering [1, 29, 30]. This approach aims to identify a limited number of genes as biomarkers within a pool of thousands. If properly set, it may be, if not the decisive method, at least a valuable support to analytical techniques already in use [31, 32].

In our study, the microarray technique was used for the first time to compare the gene expression between buffaloes treated with rbST and untreated buffaloes, in order to identify those genes, whose expression patterns could be exploited to discriminate the first group from the second.

The analysis was carried out on eight treated and eight non-treated animals in two different moments of the treatment, in order to select the genes differentially expressed for further investigation. In fact, differentially expressed genes may be the combined results of the treatment itself and some other environmental or health factors, which are often unpredictable. The genes identified in both the assays are supposed to be associated to a higher probability to be directly or indirectly influenced by the high level of rbST in serum, rather than to other random factors.

These genes were found to be 68 in the group B5 (first moment), corresponding to the sampling carried out on the fifth day after the second rbST injection, and 118 in the group D5, corresponding to the sampling carried out on the fifth day after the fourth rbST injection. From the intersection of the two sets, 28 genes were identified. Such genes were further included into a thorough investigation, carried out using the technique of real-time PCR, in order to delineate an expression pattern that characterized the group of treated animals. The genes selected are shown in Table 2:

\section{Gene Expression Analysis by Real Time PCR}

The preliminary trials on primers (Table 1) were made on genetic material extracted from untreated animals. Analysis of melting after real-time PCR showed melting temperature peaks unique and distinct for each amplicon. The amplification product sent to sequencing was found to have an identity of at least $98 \%$ with the corresponding sequences deposited in GenBank.

Over the years, the Real-time PCR has progressed in tandem with microarray analysis and, although the latter represent the preferred method for large-scale surveys and screening, real-time PCR remains the "gold standard test" in studies of gene expression, especially due to its much greater sensitivity [28]. In many studies, the real-time PCR was found to be a valid method of confirmation of microarray analysis. However, the results of the two analytical techniques are sometimes discordant. Both the biological and technical variability may have a strong impact on the results of the two methods [33,34]. This essentially occurs for the analysis of those genes, whose degree of variability is low $[34,35,36]$ and discordance of results increases by increasing the distance between the position of the microarray probe on the gene and the localization of primers [35].

In this study, by applying the Student's test on the real-time PCR responses, significant differences between controls and treated animals were found only for the following genes: AQP3, BIRC5, CdC20, IGHG1, KIF22, LMAN1, LMTK2, MZB1, NUSAP1 (Table 2). The results of this analysis are reported in graphical form in Figure 1.

\section{Linear Discriminant Analysis (LDA)}

Since the objective of this work was, at first, to develop an algorithm able to discriminate rbST-treated from untreated animals, the results of the gene expression analysis performed by real-time PCR were elaborated by applying a linear discriminant analysis. It was carried out to identify the variables (relative levels of expression of individual genes) with the greatest discriminating power. The contributions of the genes identified were used to develop a linear system for classification, from which it was obtained a response value $(\mathrm{Y})$, according to which the sample was classified 
Table 2: Genes with significant expression variability in response to microarray analysis. Highlighted in light grey: genes whose expression in the treated group was confirmed to be significantly changed compared to the control group using real-time PCR; dark gray: reference genes for relative quantification in real-time PCR.

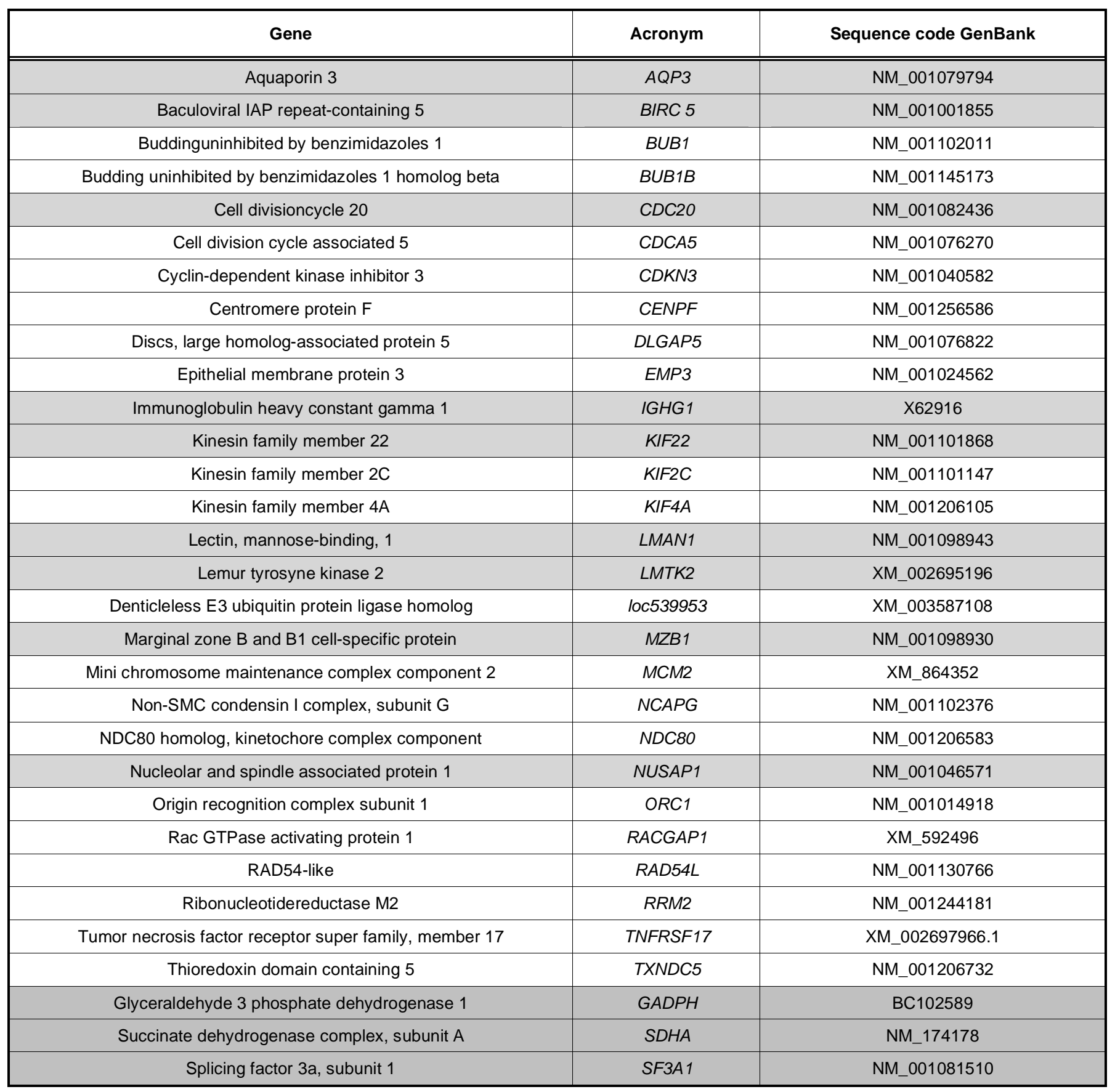

as positive (trend to 1 ) or negative (trend to 0 ). 1 and 0 are mathematically ideal values, to whom the actual responses for each analyzed sample should tend to be correctly classified. The threshold value $(0.5)$ was set to match the exact mean between the two ideal values. When the response of the linear system associated to a sample belonging to one of the two groups is closer to the ideal value of the other group, misclassification occurs. This possibility is more frequent with increasing number of samples used to develop the classifying algorithm. For this reason, part of this study was focused to the development of a post hoc analysis to determine the minimum number of samples to be included for creation of a classifying algorithm, in order to assure the least possible number of incorrect classifications. This approach is necessary when 


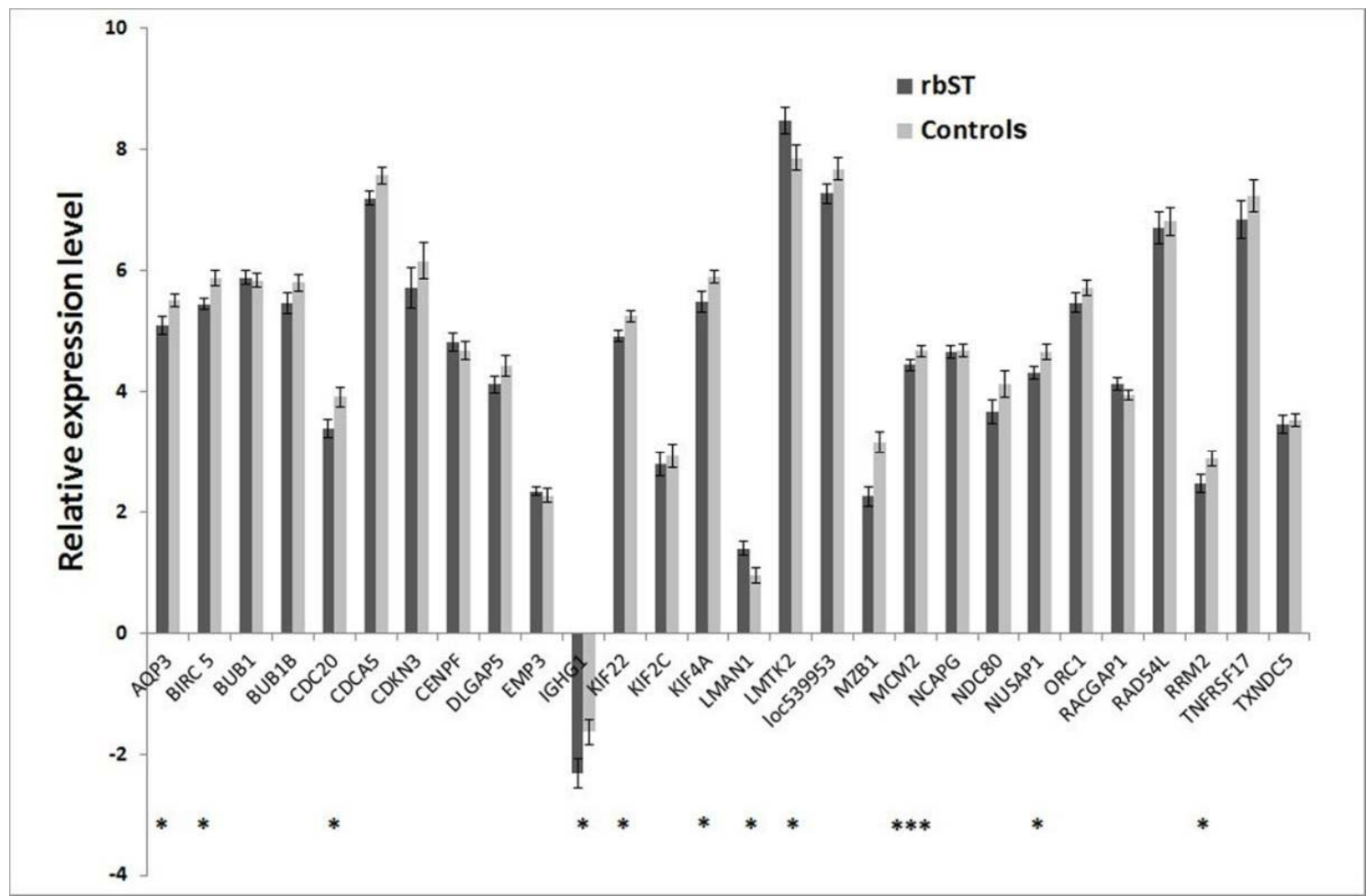

Figure 1: Relative gene expression level measured by real-time PCR in the group of rbST treated buffalos (dark) and untreated buffalos (grey). Asterisks countersign significance $\left({ }^{*} P<0.05\right.$; $\left.{ }^{* *}{ }^{*} P<0.001\right)$.

dealing with complex systems with a very high number of variables, for which it is difficult to establish a priori such a number.

The analysis on the stabilization of variance shows that the difference between the variance calculated as the mean of the variances of each variable on a certain sampling moment and that calculated by adding the

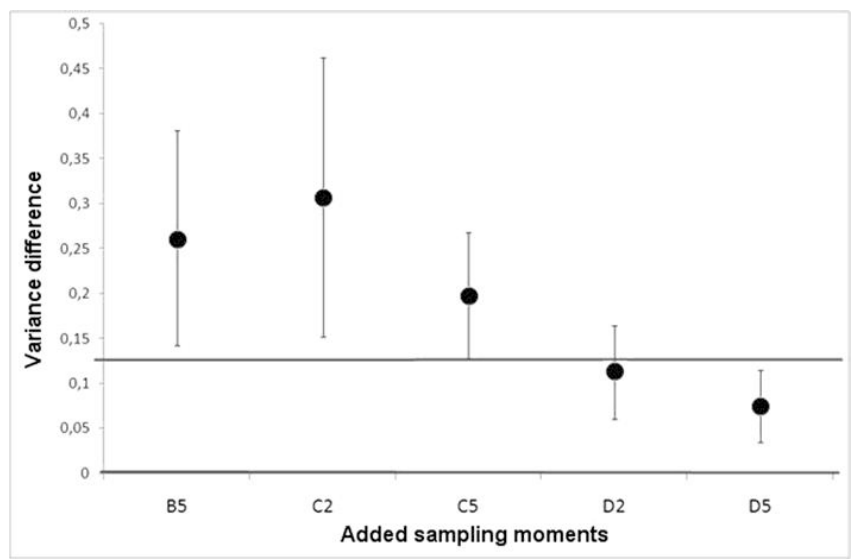

Figure 2: Difference related to the variances calculated by progressively increasing the number of sampling times The points represent the mean of the differences calculated individually on all variables (expression levels of each gene) $\pm 95 \%$ confidence interval. The red lines represent the upper and lower boundaries of the range within which the $95 \%$ confidence interval should be included for considering the variance as stabilized. samples of the next sampling moment decreases as the number of sampling moments (and thus the number of samples) increases (Figure 2). An acceptable level of stabilization appears to be achieved when the sub-group " 5 sampling moments" (D5) is added, since the difference between the two successive subgroups presents a confidence interval entirely included within the zone of acceptance.

By developing a classifying linear system for each sampling time (B2; B5; etc...) and for each possible combination of sampling times (1 to 6 times; i.e B2xC5; B2xC5xD2; B2xC5xD2xD5; etc...) and afterwards applying such a system on the total pool of samples available, it could be observed that the absolute classification error decreases by increasing the number of sampling moments used for developing the algorithm (Figure 3).

On the contrary, when elaborating an algorithm using a certain sample group, after applying the algorithm to the same group, the percentage of classification errors increase by increasing the number of samples included in the statistic unit, tending to stabilize when the sample size is appropriate to produce a reliable classifying algorithm (Figure 4).

The set of these results shows that the reliability of a classifying algorithm cannot prescind a suitable 
number of subjects to be included in the calculation, reasonably representative of the entire population. The lack of an investigation aimed at determining this number may therefore lead to results with low predictive value. A demonstration of this statement may be extrapolated by reporting an example of the case in which the algorithm is created starting from a limited number of samples (Figure 5). The graph shows that, actually, using data relating to a single sampling moment, the values associated to the treated animals and to controls are distributed in an area very close to the ideal values of 1 and 0 , respectively. In all cases examined in the subgroups formed by a sampling moment, the misclassification was always equal to 0 .

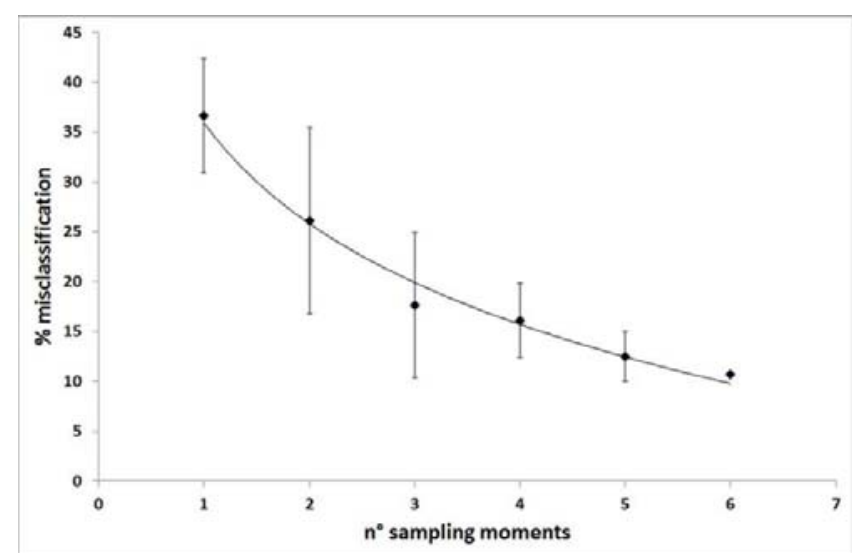

Figure 3: Absolute errors of classification (\% of $\mathrm{FN}+\mathrm{FP}$ ) obtained by applying, to the set of all samples $(n=92)$, the linear systems developed by taking into consideration the moments of sampling (B2; B5; C2; C5; D2; D5) individually $\left(n^{\circ}\right.$ total combinations $\left.=6\right)$; in combinations of 2 ( $n^{\circ}$ total combinations $=15$ ); of 3 ( $n^{\circ}$ of total combinations $=20$ ); of 4 ( $n^{\circ}$ of total combinations $=15$ ); of 5 ( $n^{\circ}$ of total combinations $=6)$; and $6\left(n^{\circ}\right.$ of total combinations $\left.=1\right)$. The points represent the mean \pm standard error of the different combinations.

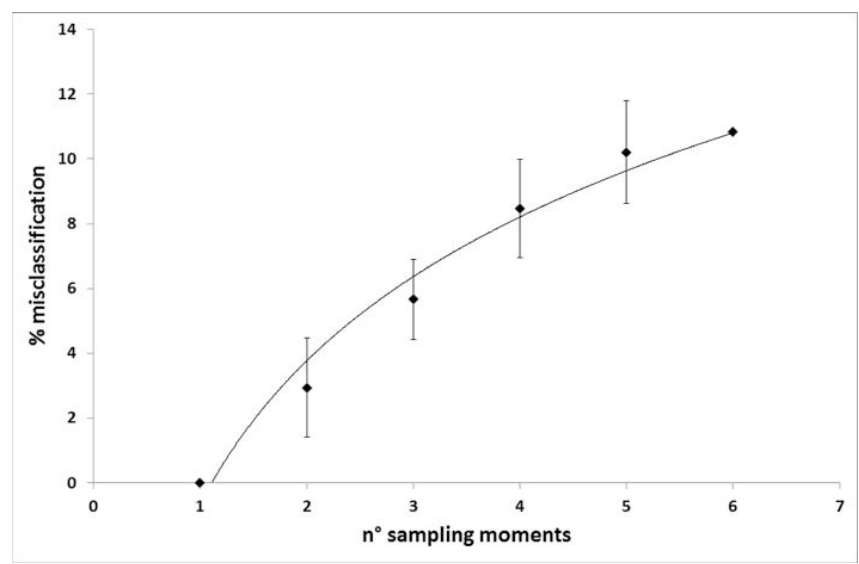

Figure 4: Errors of classification (\% of $\mathrm{FN}+\mathrm{FP}$ ) obtained by developing linear systems of subgroups consisting of $n=1 ; 2$; $3 ; 4 ; 5 ; 6$ sampling times (B2; B5; C2; C5; D2; D5), and in all possible combinations. The points represent the mean \pm standard error of the different combinations.

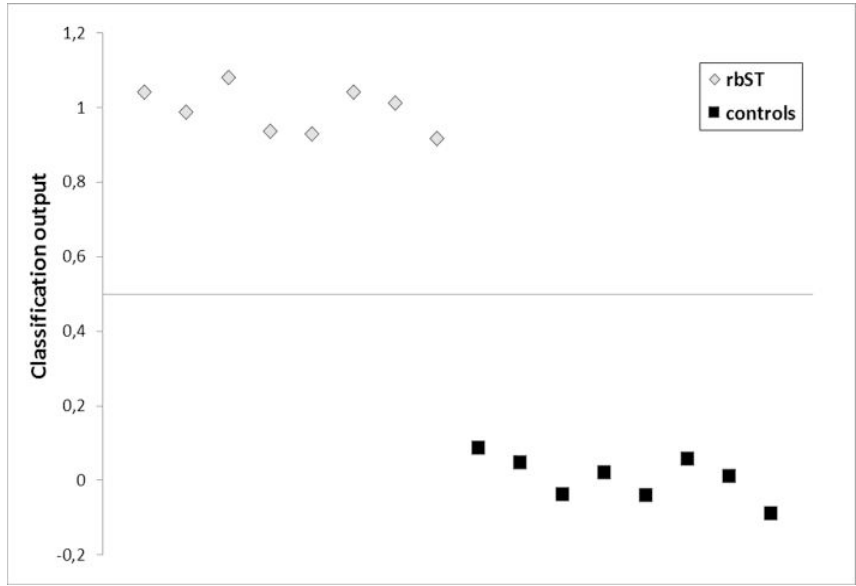

Figure 5: Example on the application of a classifying linear system developed by taking into consideration a subgroup formed by a single sampling moment $\left(n^{\circ}\right.$ treated $=8 ; n^{\circ}$ controls $=8$ ). The discrimination threshold was fixed at 0.5 .

By increasing the sampling moments (sub-groups of $\mathrm{n}=3$ ), the sharp difference between the values attributed to the treated and the values attributed to the controls tends to be reduced, with a less homogeneous distribution pattern (Figure 6), unto the other extreme, showed in the Figure 7, where the algorithm is created and applied by taking into consideration all the groups.

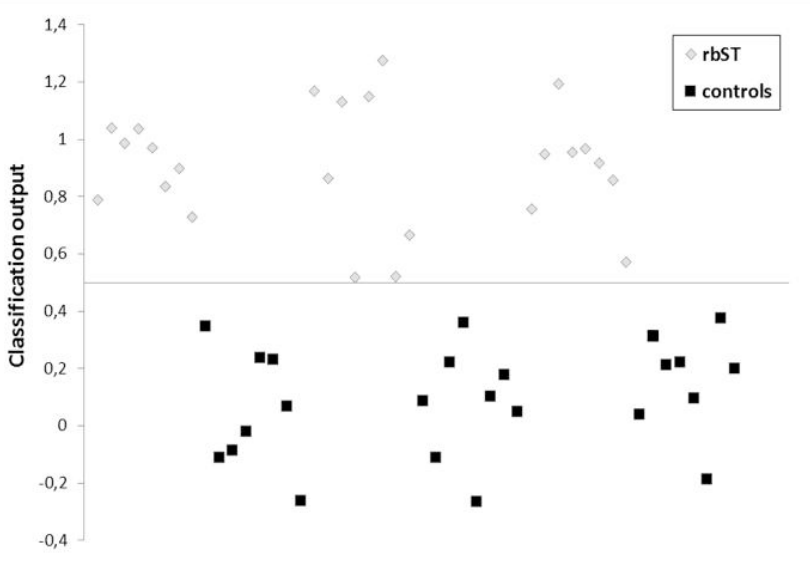

Figure 6: Example on the application of a classifying linear system developed by taking into consideration a subgroup formed by three sampling moments $\left(\mathrm{n}^{\circ}\right.$ treated $=24 ; \mathrm{n}^{\circ}$ controls $=24$ ). The discriminator threshold was fixed at 0.5 .

The pattern of distribution of the values associated with the samples is less homogeneous and there is a number of misclassified samples.

The latter example represents the final application of the algorithm described below:

$$
\begin{gathered}
Y=0.328289+0.120226{ }^{*} X 1-X 2+0.2404{ }^{*} \\
0.441559+0.112452{ }^{*} X 3{ }^{*} X 4-X 5{ }^{*} 0.1268-0.15414 \\
{ }^{*} X 6-0.17974+X 7
\end{gathered}
$$




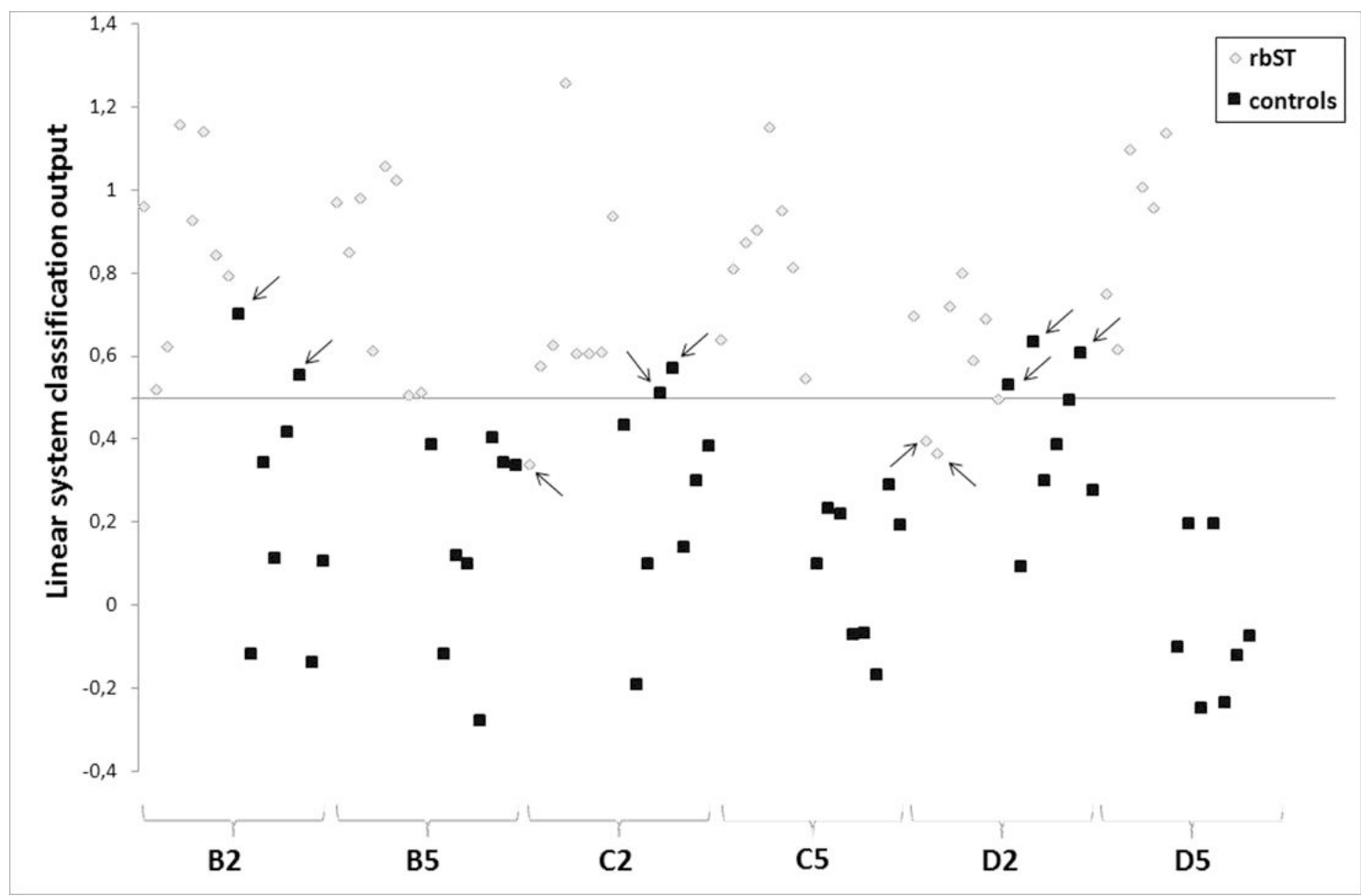

Figure 7: Creation and application of the classifying linear system using the totality of the samples. The percentage of FN obtained is $6.5 \%$, while that of FP is $15.2 \%$. The misclassified samples are indicated by arrows.

where

$\mathrm{X} 1=$ relative gene expression levels associated with Bub1

$\mathrm{X} 2$ = relative gene expression levels associated with CDCA5

$\mathrm{X} 3$ = relative gene expression levels associated with LMAN

$\mathrm{X} 4$ = relative gene expression levels associated with LMTK2

X5 $=$ relative gene expression levels associated with loc539953

$\mathrm{X} 6$ = relative gene expression levels associated with LZB1

$\mathrm{X} 7$ = relative gene expression levels associated with $\mathrm{Ndc} 80$

This linear system applied to the whole statistical population returns a false-negative rate corresponding to approximately $6.5 \%$ and a false positive rate of about $15.2 \%$ (Figure 7). Due to the fact that "Only those analytical techniques... that .... have a false compliant rate of $<5 \%$ ( $\beta$-error) at the level of interest shall be used for screening purposes in conformity with
Directive 96/23/EC "(Decision 657/2002) [6], the performance of the system developed in this study do not fully satisfy the requirements imposed by the law.

By setting the experimental design in order to choose too a low number of samples (in our case, too a low number of sampling moments), the results of this work might have been fully compliant with the requirements of the Dec 657/2002 [6]. This demonstrate that each experimental design involves a certain degree of discretion and strongly suggests that the reliability of each algorithm should be fully demonstrated before drawing any conclusion.

\section{CONCLUSIONS}

The choice of biomarkers such as the variation of gene expression in white blood cells to identify treated buffalos with rbST was shown not to be useful for the development of a discriminant algorithm applicable in field. This was due to the fact that, when a proper number of samples were included in the study, the final false compliant rate exceeded $5 \%$ ( $\beta$-error), the threshold imposed by Decision 2002/657/EC for screening methods [6].

Furthermore, in this study was shown as a major risk related to a wrong evaluation of the sample size is the creation of a model that would bring to 
underestimate the $\beta$-error and, therefore, to wrongly consider an analytical system as suitable. For this reason, the number of samples to be included for algorithm development is a key factor for the reliability of discrimination and should be carefully evaluated, by applying statistics such as the analysis of the stabilization of variance.

\section{ACKNOWLEDGEMENTS}

The study is part of a project financed by the Italian Ministry of Health (project code: GR-2009-1606346).

\section{REFERENCES}

Cannizzo FT, Pegolo S, Starvaggi Cucuzza L, et al. Gene expression profiling of thymus in beef cattle treated with prednisolone. Res Vet Sci 2013; 95: 540-7. http://dx.doi.org/10.1016/j.rvsc.2013.03.025

De Jager N, Hudson NJ, Reverter A, et al. Chronic exposure to anabolic steroids induces the muscle expression of oxytocin and a more than fiftyfold increase in circulating oxytocin in cattle. Physiol Genom 2011; 43: 467-78. http://dx.doi.org/10.1152/physiolgenomics.00226.2010

Kinkead RA, Elliott CT, Cannizzo FT, Biolatti B, Mooney MH. Proteomic identification of plasma proteins as markers of growth promoter abuse in cattle. Anal Bioanal Chem 2015; 407: 4495-507. http://dx.doi.org/10.1007/s00216-015-8651-0

Ludwig SKJ, Smits NGE, Cannizzo FT, Nielen MWF. Potential of treatment-specific protein biomarker profiles for detection of hormone abuse in cattle. J Agric Food Chem 2013; 61: 4514-9.

http://dx.doi.org/10.1021/jf4004972

Pinel G, Weigel S, Antignac JP, et al. Targeted and untargeted profiling of biological fluids to screen for anabolic practices in cattle. Trends Anal Chem 2010; 29: 1269-80. http://dx.doi.org/10.1016/.t.trac.2010.06.010

[6] Commission Decision 2002/657/EC of 12 August 2002 implementing Council Directive 96/23/EC concerning the performance of analytical methods and the interpretation of results Official Journal of the European Community L 221: 8-36.

[7] Council Decision 1999/879/EC of 17 December 1999 concerningthe Placing on the Market and Administration of bovineSomatotrophin(BST) and repealing Decision 90/218/EEC Official Journal of the European Community L331: 71-72.

[8] Le Breton MH, Rochereau-Roulet S, Pinel G, Cesbron N, Le Bizec B. Elimination kinetic of recombinant somatotropin in bovine. Anal Chim Acta 2009; 637: 121-7. http://dx.doi.org/10.1016/j.aca.2008.09.003

[9] Le Breton MH, Rochereau-Roulet $S$, Chéreau S Pinel G, Delatour T, Le Bizec B. Identification of cows treated with recombinant bovine somatotropin. J Agric Food Chem 2010; 58: 729-33.

http://dx.doi.org/10.1021/j903032q

[10] Smits NG, Blokland MH, Wubs KL, Nessen MA, van Ginkel LA, Nielen MW. Monolith immuno-affinity enrichment liquid chromatography tandem mass spectrometry for quantitative protein analysis of recombinant bovine somatotropin in serum. Anal Bioanal Chem 2015; 407: 6041-50. http://dx.doi.org/10.1007/s00216-015-8775-2

[11] Castigliego L, lannone G, Grifoni G, et al. Natural and recombinant bovine somatotropin: immunodetection with a sandwich ELISA. J Dairy Res 2007; 74: 79-85. http://dx.doi.org/10.1017/S0022029906002159
[12] Suárez-Pantaleón $\mathrm{C}$, Huet AC, Kavanagh $\mathrm{O}$, et al. Production of polyclonal antibodies directed to recombinant methionyl bovine somatotropin. Anal Chim Acta 2013; 761: 186-93.

http://dx.doi.org/10.1016/j.aca.2012.11.041

[13] Zhao X, McBride BW, Trouten-Radford LM, Golfman L, Burton $\mathrm{JH}$. Somatotropin and insulin-like growth factorconcentrations in plasma and milk after daily or sustainedrelease exogenous somatotropin administrations. Domest Anim Endocrinol 1994; 11: 209-16. http://dx.doi.org/10.1016/0739-7240(94)90028-0

[14] Doué M, Dervilly-Pinel G, Cesbron N, et al. Clinical biochemical and hormonal profiling in plasma: a promising strategy to predict growth hormone abuse in cattle. Anal Bioanal Chem 2015; 407: 4343-9. http://dx.doi.org/10.1007/s00216-015-8548-y

[15] Ludwig SKJ, Smits MGE, Bremer MGEG, Nielen MWF. Monitoring milk for antibodies against recombinant bovine somatotropin using a microsphere immunoassay-based biomarker approach. Food Control 2012; 26: 68-72. http://dx.doi.org/10.1016/j.foodcont.2011.12.011

[16] Pinel G, Buon R, Aviat $F$, et al. Recombinant bovine somatotropin misuse in cattle Evaluation of Western blotting and $2 \mathrm{D}$ electrophoresis methods on biological samples for the demonstration of its administration. Anal Chim Acta 2005; 529: 41-6.

http://dx.doi.org/10.1016/j.aca.2004.07.063

[17] Rochereau-Roulet S, Gaudin I, Chéreau S, et al. Development and validation of an enzyme-linked immunosorbent assay for the detection of circulating antibodies raised against growth hormone as a consequence of rbST treatment in cows. Anal Chim Acta 2011; 700: 189-93. http://dx.doi.org/10.1016/.aca.2011.01.035

[18] Smits NG, Bremer MG, Ludwig SK, Nielen MW Development of a flow cytometric immunoassay for recombinant bovine somatotropin-induced antibodies in serum of dairy cows. Drug Testing and Anal 2012; 4: 362-7. http://dx.doi.org/10.1002/dta.336

[19] Castigliego L, Armani A, Grifoni G, et al. Effects of growth hormone treatment on the expression of somatotropic axis genes in the skeletal muscle of lactating Holstein cows. Dom Anim Endocrinol 2010; 39: 40-53. http://dx.doi.org/10.1016/i.domaniend.2010.02.001

[20] Castigliego L, Li XN, Armani A, et al. Somatotropic gene response to recombinant growth hormone treatment in buffalo leucocytes. Biol Chem 2011; 392: 1145-54 http://dx.doi.org/10.1515/BC.2011.187

[21] Smyth GK. Limma: linear models for microarray data. In: Gentleman R, Carey V, Dudoit S, Irizarry R, Huber W, editors. Bioinformatics and Computational Biology Solutions using R and Bioconductor. New York: Springer 2005; pp. 397-420.

http://dx.doi.org/10.1007/0-387-29362-0 23

[22] Jeay S, Sonenshein GE, Postel-Vinay MC, Kelly PA, Baixeras E. Growth hormone can act as a cytokine controlling survival and proliferation of immune cells: new insights into signaling pathways. Mol Cell endocrinol 2002; 188: 1-7. http://dx.doi.org/10.1016/S0303-7207(02)00014-X

[23] Welniak LA, Sun R, Murphy WJ. The role of growth hormone in T-cell development and reconstitution. J Leukocyte Biol 2002; 71: 381-7.

[24] Velkeniers B, Dogusan Z, Naessens F, Hooghe R, HooghePeters EL. Prolactin growth hormone and the immune system in humans. Cell Mol Life Sci 1998; 54: 1102-8. http://dx.doi.org/10.1007/s000180050239

[25] Elvinger F, Hansen PJ, Head HH, Natzke RP. Actions of bovine somatotropin on polymorphonuclear leukocytes and lymphocytes in cattle. J Dairy Sci 1991; 74: 2145-2152. http://dx.doi.org/10.3168/jds.S0022-0302(91)78387-2 
[26] Burton JL, McBride BW, Kennedy BW, Burton JH, Elsasser $\mathrm{TH}$, Woodward B. Hematological profiles in dairy cows treated with recombinant bovine somatotropin. J Anim Sci 1992; 70: 1488-95.

[27] Khaliq T, Rahman ZU. Haematological Studies of Nili-Ravi Buffaloes Injected with Recombinant Bovine Somatotropin. Pak Vet J 2010; 30: 53-7.

[28] Canales RD, Luo Y, Willey JC, et al. Evaluation of DNA microarray results with quantitative gene expression platforms. Nat Biotechnol 2006; 24: 1115-22. http://dx.doi.org/10.1038/nbt1236

[29] Carraro L, Ferraresso S, Cardazzo B, et al. Expression profiling of skeletalmuscle in young bulls treated with steroidal growth promoters. Physiol Genom 2009; 38: 13848. http://dx.doi.org/10.1152/physiolgenomics.00014.2009

[30] Pegolo S, Cannizzo FT, Biolatti B, Castagnaro M, Bargelloni L. Transcriptomic profiling as a screening tool to detect trenbolone treatment in beef cattle. Res Vet Sci 2014; 96: 472-81. http://dx.doi.org/10.1016/j.rvsc.2014.03.020

[31] Reiter M, Walf VM, Christians A, Pfaffl MW, Meyer $\mathrm{HH}$. Modification of mRNA expression after treatment with anabolic agents and the usefulness for gene expressionbiomarkers. Anal Chim Acta 2007; 586: 73- 81. http://dx.doi.org/10.1016/j.aca.2006.10.049

[32] Toffolatti L, Rosa Gastaldo L, Patarnello T, et al. Expression analysis of androgen-responsive genes in the prostate of vealcalvestreated with anabolichormones. Domest Anim Endocrinol 2006; 30: 38-55.

http://dx.doi.org/10.1016/j.domaniend.2005.05.008

[33] Chuaqui RF, Bonner RF, Best CJM, et al. Post-analysis follow-up and validation of microarray experiments. Nat Genet 2002; 32: 509-14. http://dx.doi.org/10.1038/ng1034

[34] Wurmbach E, Yuen T, Sealfon SC. Focused microarray analysis. Methods 2003; 31: 306-16. http://dx.doi.org/10.1016/S1046-2023(03)00161-0

[35] Etienne W, Meyer MH, Peppers J, Meyer RA Jr. Comparison of mRNA gene expression by RT-PCR and DNA microarray. BioTechniques 2004; 36: 618-21.

[36] Rajeevan MS, Vernon SD, Taysavang N, Unger ER Validation of array-based gene expression profiles by realtime (kinetic) RT-PCR. J Mol Diagn 2001; 3: 26-31. http://dx.doi.org/10.1016/S1525-1578(10)60646-0 